\title{
HISHANI MIZUNO, Gérard de Nerval et la poésie en vers. Des odelettes aux sonnets
}

\section{Lise Sabourin}

\section{(2) OpenEdition}

\section{Journals}

Édition électronique

URL : https://journals.openedition.org/studifrancesi/22956

DOI : $10.4000 /$ studifrancesi.22956

ISSN : 2427-5856

Éditeur

Rosenberg \& Sellier

\section{Édition imprimée}

Date de publication : 1 avril 2020

Pagination : 198

ISSN : 0039-2944

\section{Référence électronique}

Lise Sabourin, « HISHANI mIZUno, Gérard de Nerval et la poésie en vers. Des odelettes aux sonnets 》, Studi Francesi [En ligne], 190 (LXIV | I) | 2020, mis en ligne le 01 mai 2020, consulté le 02 août 2021. URL http://journals.openedition.org/studifrancesi/22956 ; DOI : https://doi.org/10.4000/studifrancesi. 22956

Ce document a été généré automatiquement le 2 août 2021

\section{(c) (i) (9) $\Theta$}

Studi Francesi è distribuita con Licenza Creative Commons Attribuzione - Non commerciale - Non opere derivate 4.0 Internazionale. 


\title{
HISHANI MIZUNO, Gérard de Nerval et la poésie en vers. Des odelettes aux sonnets
}

\author{
Lise Sabourin
}

\section{RÉFÉRENCE}

HISHANI MIZUNO, Gérard de Nerval et la poésie en vers. Des odelettes aux sonnets, Paris, Champion, 2018, 388 pp.

1 Le professeur Hishani Mizuno adopte un point de vue différent de bien des commentaires sur l'œuvre poétique de Nerval: il veut «établir un dialogue face à face avec Nerval, et non le lire par le biais des images de la folie, du mysticisme ou du mythe personnel». C'est dire que sa position de critique extérieur aux habitudes francofrançaises lui permet d'éclairer tout simplement l'œuvre pas à pas, par l'élucidation des allusions érudites de Nerval et la mise en situation au cœur des débats contemporains sur la poésie.

2 La première partie (pp.19-105) étudie les Odelettes de 1830 à 1834: outre l'état de la production poétique à l'époque des trois Glorieuses, notamment chez Hugo, H. Mizuno discerne bien dans celles de 1831 l'abandon des motifs héroï-comiques au profit de l'influence des poètes de la Pléiade remis en visibilité par Sainte-Beuve, puis explore le cheminement vers le renouveau dans celles de 1834 .

3 La deuxième partie (pp. 109-235) se penche sur les sonnets de 1842 à 1845, là aussi mis dans le contexte de la pratique de cette forme en 1840 et étudiant les sonnets du manuscrit Dumesnil de Gramont, ceux inclus dans une lettre à Victor Loubens, qui reflètent certes l'état psychique de leur auteur en 1841, mais aussi les discussions de ce début de décennie sur la poésie. La reprise de quelques sonnets en 1844-1845, en lien avec le réveil du sentiment religieux, aboutit aux sonnets initiés par «Le Christ aux Oliviers» et aux Vers dorés de 1844-1845.

4 Enfin la troisième partie (pp. 239-344) s'élance de La Bohême galante et des Petits Châteaux de Bohême en 1852, qui cherchent à s'affranchir des habitudes poétiques, 
jusqu'aux ultimes Chimères, intégrées à la prose musicale des Filles du feu, qui accomplissent sa poétique personnelle: Nerval ne renonce pas à ces formes concentrées, finalement persistantes des odelettes aux sonnets, mais y introduit le mystère de l'unicité de l'être à travers les métamorphoses du moi.

5 La méthode s'avère très payante: le lecteur peut utiliser le commentaire de chaque poème, vers après vers, en le confrontant aux recueils, dans l'ordre de composition des œuvres, et discerner de ce fait avec précision l'itinéraire nervalien en lien et en écart à la fois avec ses confrères. Il ne s'agit pas d'une rupture avec son époque, ni avec ses débuts de traducteur de la littérature germanique, mais d'un approfondissement des liens secrets entre les chants du XII ${ }^{e}$ siècle, les poésies de Ronsard et l'univers magique des chansons populaires, avec leur pratique de la rime, de l'assonance et du hiatus. Comme le «fou sublime» qu'est le second Faust goethéen, mais dans une inspiration intimiste, Gérard scrute l'immédiateté de l'instant, la force du souvenir, la griserie de la sensation, la fusion avec la nature, lorsque ses visions parviennent à la faire entrer en communion avec le monde des esprits. 